\title{
ACTIVIDAD GENOTÓXICA DE AGUAS ANTES Y DESPUES DE CLORAR EN LA PLANTA DE POTABILIZACIÓN EMPOPAMPLONA
}

\section{Iván Meléndez Gélvez ${ }^{1}$., Enrique Pardo Perez²., Alfonso Quijano Parra ${ }^{3}$}

1 Universidad de Pamplona, Pamplona, Colombia, Facultad de Ciencias Básicas, Grupo de Investigación en Biología Molecular.

2 Universidad de Córdoba, Montería, Córdoba, Colombia. Área de Genética, Departamento de Biología.

3 Universidad de Pamplona, Colombia, Facultad de Ciencias Básicas, Departamento de Química. Grupo de Investigación en Química

Resumen: La salud humana está estrechamente ligada a la calidad del agua que se consume, sin embargo cada día son liberados contaminantes que ponen en riesgo su calidad. Las aguas de consumo pueden contaminarse con pesticidas, desechos industriales, aguas negras y subproductos de la cloración, dichos compuestos pueden inducir tumores e incluso la muerte, cuando la exposición es a largo plazo y dosis bajas. La planta de purificación de agua del municipio de Pamplona (EMPOPAMPLONA) se abastece de 4 efluentes que atraviesan zonas agrícolas, por lo tanto las aguas pueden recibir pesticidas, ya que en estas zonas, ellos son utilizados indiscriminadamente. También pueden contaminarse con desechos domiciliarios debido a que las fuentes abastecedoras pasan por caseríos. Además, las aguas también pueden recibir subproductos del proceso de cloración, los cuales se ha demostrado son fuertes mutágenos. El estudio contempló la determinación de la genotoxicidad en aguas de tres sitios diferentes: Zona 1, agua antes de ingresar a la planta de tratamiento; zona 2, agua después de haber sido tratada y zona 3, agua después de haber sido clorada. Cada ensayo se realizó por triplicado. Se utilizó la prueba de ANOVA a una vía para determinar el nivel de significancia entre el tratamiento y control. Los resultados mostraron un incremento significativo de la genotoxicidad en los tres sitios analizados $(p<0.01)$, lo que nos evidencia la presencia de compuestos genotóxicos, los cuales pueden constituir un riesgo para la población expuesta, dado que se sabe de la estrecha relación que existe entre la exposición a mutágenos y la aparición enfermedades como el cáncer.

Palabras clave: Agua de consumo humano, Cáncer, Ensayo cometa Genotoxicidad, Pamplona, Colombia

\section{Activity genotoxic water before and after the chlorinate water treatment plant Empopamplona}

Abstract: Human health is strongly linked to the quality of water consumed, however every day they are released pollutants that 
threaten their quality. The drinking water may be contaminated with pesticides, industrial wastes, sewage and chlorination byproducts, such compounds may induce tumors and death, when the exposure is long-term and low dose. The water purification plant in the municipality of Pamplona (EMPOPAMPLONA) is supplied by 4 effluent that cross agricultural areas, so water can get pesticides, since in these areas, they are used indiscriminately. They can also be contaminated by domestic waste because the supply sources pass through villages. Furthermore, water may also receive chlorination byproducts, which have been shown are strong mutagens. The study included the determination of genotoxicity in waters from three different sites: Zone 1, water prior to entering the treatment plant; zone 2, water after being treated and zone 3, water after being chlorinated. Each assay was performed in triplicate. One-way ANOVA was used to determine the level of significance between treatment and control. The results showed a significant increase of genotoxicity in the three analyzed sites $(p<0.01)$. The results showed a significant increase of genotoxicity in the three analyzed sites ( $p<0.01)$, which shows us the presence of genotoxic compounds, which may constitute a risk to the exposed population, as is known of the close relationship between exposure to mutagens and diseases such as cancer.

Keywords: Drinking water, cancer, comet assay, genotoxicity, Pamplona, Colombia

\footnotetext{
*Para citar este artículo: Meléndez Gélvez I., Pardo Perez E., Quijano Parra A. Actividad genotoxica de aguas antes y después de clorar en la planta de potabilización Empopamplona. Revista Bistua.2015.13(2):12-23
}

+ Autor para el envió de correspondencia y la solicitud de las separatas: Melendez Gelvez I. Universidad de Pamplona. Facultad de Ciencias Básicas. Departamento de Biología. email:imgelvez@unipamplona.edu.co 


\section{INTRODUCCIÓN}

En Colombia, la calidad del agua de consumo solo se determina teniendo en cuenta parámetros fisicoquímicos y microbiológicos, pero se desconoce por completo el control relacionado con compuestos mutacarcinogénicos, que pueden contaminar las aguas que abastecen las plantas de tratamiento de aguas de consumo. Es muy posible que gran parte de nuestras aguas de consumo contengan mutágenos y/o carcinógenos ya que las aguas tratadas para consumo humano pueden contaminarse con sustancias químicas mutacarcinogénicas provenientes de la contaminación con agroquímicos, desechos industriales y aguas negras, además, por acción de la desinfección con cloro se forman nuevos mutacarcinógenos por reacción del cloro con el material orgánico que contiene el agua ${ }^{1,2}$. En mayor o menor grado la población humana está inevitablemente expuesta a pesticidas, los cuales contribuyen a la contaminación ambiental por medio de productos degradados en aire, suelo, agua y alimentos; este contacto a largo plazo puede inducir daño en las poblaciones, perturbando órganos, tejidos, sistemas entre otros ${ }^{3}$. Cada vez hay más pruebas de la relación de la exposición de pesticidas con la incidencia de enfermedades crónicas humanas, pues son considerados como la principal causa de mortalidad en el nuevo mundo, lo que representa más del $60 \%$ de todas las muertes ${ }^{4}$. Muchos pesticidas han sido clasificados como cancerígenos según la Agencia de Protección Ambiental de Estados Unidos ${ }^{5}$ y la Agencia Internacional para la Investigación sobre el Cáncer ${ }^{6}$.
Según ${ }^{7}$ más de la mitad de los pesticidas han resultado ser potencialmente carcinogénicos. Se ha encontrado que pesticidas organofosforados como el malatión y el paratión inducen tumores mamarios en ratas $^{8}$. La mutagenicidad y carcinogenicidad de muchos pesticidas se ha demostrado ampliamente ${ }^{9,10,11}$.

En muchos países se ha demostrado que el agua potable contiene compuestos mutagénicos polares no volátiles como los hidrocarburos policíclicos aromáticos (HPA) ${ }^{12}$. Los hidrocarburos policíclicos aromáticos HAP constituyen una clase importante de contaminantes ambientales generados por la combustión de la materia orgánica, muchos PAHs, en particular los compuestos más grandes de cinco y seis anillos que pueden ser metabolizados a diol epóxidos son mutágenos y carcinógenos ${ }^{13}$. Los PHA se encuentran en la lista de contaminantes prioritarios debido a sus propiedades carcinogénicas y mutagénicas en general, aunque su propiedad carcinogénica varía de un compuesto a otro ${ }^{14}$.

El cloro es el desinfectante más ampliamente usado para la desinfección del agua, porque es extremadamente efectivo y muy económico, sin embargo varios estudios realizados desde 1970 revelan que la cloración del agua genera subproductos potencialmente dañinos ${ }^{15}$. Los principales subproductos de cloración los podemos agrupar en trihalometanos (THM) y acidos haloacéticos, dentro de los cuales, los más importantes son: haloacetonitrilos (HANs), halocetonas (HCs), tricloronitrometane (cloropicrin, $\mathrm{CP})$, tricloroacetaldehido ${ }^{16} \mathrm{~N}$ nitrosaminas $^{17} \quad$ aldehidos $^{18}$ and ácidos carboxylicos ${ }^{19}$. Varios estudios epidemiológicos han 
mostrado que el consumo de agua clorada está asociado con un incremento en el riesgo de cáncer de vejiga y colorectal ${ }^{20,21,22}$. El 3cloro-4- (dicloro-metil) -5-hidroxi-2 $(5 \mathrm{H})$-furanona $(\mathrm{MX})$, un trihalometano encontrado en el agua potable, es un subproducto de desinfección, que se forma a partir de la reacción de los ácidos húmicos y cloro en el agua cruda. El MX induce cáncer en múltiples sitios en ratas macho y hembra, actúa como promotor e iniciador de tumores, promueve la formación de tumorales en roedores modificados genéticamente, en numerosas pruebas in vitro ha evidenciado actividad genotóxica, ha mostrado ser un potente inhibidor de la comunicación intercelular $^{23}$. El MX ha sido clasificado en el grupo $2 \mathrm{~B}$ (posiblemente carcinogénico para los humanos) por la Agencia Internacional para la Investigación sobre el Cáncer (IARC), ya que es un potente genotóxico en una amplia variedad de ensayos genéticos in vitro y es capaz de inducir tumores en múltiples órganos de ratas ${ }^{24}$. Para evaluar la genotoxicidad en diferentes organismos, mundialmente se ha utilizado el ensayo cometa (electroforesis en gel de células individuales, SCGE), porque es una técnica sencilla, cómoda, rápida y sensible para la evaluación de daños en el ADN y la determinación de genotoxicidad. Puede detectar rupturas en las cadenas de DNA inducidas química o físicamente en células individuales de diversos tipos. En los últimos años, el ensayo cometa ha sido ampliamente utilizado en la evaluación de daño del ADN, la vigilancia biológica, la genotoxicidad, la evaluación del tratamiento del cáncer y muchos estudios de campo.
La planta de purificación de agua del municipio de Pamplona (EMPOPAMPLONA), se abastece de 4 microcuencas: Ucuques, Morronegro, El Rosal o el Volcán y Cariongo o Monteadentro. Estas atraviesan las veredas Monteadentro, García, Alto Grande, Rosal y Navarro). La cobertura vegetal está constituida por áreas de misceláneos con cultivos transitorios de maíz, papa, arveja, fríjol, cultivos semipermanentes como fresa, arracacha; cultivos permanentes como curuba, morón, tomate de árbol, lulo; como también áreas en pastos y rastrojos, por lo tanto las quebradas pueden recibir lixiviados cargados con pesticidas ya que recorren zonas agrícolas, también pueden recibir desechos domiciliarios por pasar por caseríos. Cabe resaltar que el tratamiento que se le hace al agua utilizando cloro como desinfectante, también puede aportar compuestos mutagénicos debido a la reacción de este con el material orgánico. Esto es preocupante porque los mutágenos presentes en el agua de consumo llegan continuamente a la población en cantidades muy pequeñas que pueden causar daño genético acumulable, que origina enfermedades tales como el cáncer y enfermedades hereditarias ${ }^{25,1}$. Preocupados por los reportes que a menudo están surgiendo alrededor del mundo con respecto a la presencia de mutágenos en aguas de consumo, realizamos este estudio con el fin de evaluar la genotoxicidad y mutágenicidad inducida por aguas antes y después de ser tratadas con cloro en una planta de potabilización en Pamplona Norte de Santander.

\section{METODOLOGIA}

\section{TOMA DE MUESTRAS}

Las muestras se tomaron a cincuenta centímetros de 
profundidad, el volumen total de cada muestra fue de 100L. Se captó en tres sitios diferentes: Zona 1, aguas inmediatamente antes de entrar a la planta de tratamiento de Empopamplona (Agua cruda). Zona 2 , aguas tomadas después de pasar por sedimentación, coagulación y floculación (Agua tratada) y Zona 3: Aguas después del proceso de cloración (Agua clorada).

\section{CONCENTRACIÓN EXTRACCIÓN DEL MATERIAL ORGÁNICO DEL AGUA}

Para concentrar el material orgánico, las muestras de agua se pasaron por una columna que contenía 100 gramos de resina XAD-2, a una velocidad aproximada de $15 \mathrm{ml} / \mathrm{min}$. La elusión se hizo con 3 volúmenes de acetona seguida de tres volúmenes de dietil eter. Los eluyentes se retiraron por rotaevaporación a baja presión y temperatura, hasta alcanzar la sequedad. El extracto seco se disolvió en DMSO al 12\%. Antes de usar las resinas XAD, se lavaron consecutivamente cada 24 horas, con metanol, acetona y metanol. En el momento de usar la XAD se enjuagó tres veces con agua destilada.

\section{DETECCIÓN DE DAÑO DEL DNA POR EL ENSAYO COMETA}

Para detectar ruptura del DNA se utilizó el ensayo "COMETA" en microgel de una célula. Se sigue la metodología propuesta $\operatorname{por}^{26}$ y modificada por $^{27}$. En resumen, Se trataron 40.000 células o linfocitos con tres dosis $(100 \mu \mathrm{g}, 200 \mu \mathrm{g}$ y 400 $\mu g)$ de extractos de agua, se incubaron por un periodo de 1 hora a $37^{\circ} \mathrm{C}$, las placas se sumergieron como mínimo $1 \mathrm{~h}$ en solución de lisis. Las placas se lavaron con PBS y se colocaron en una unidad de electroforesis horizontal con un buffer $\mathrm{pH}>13 \mathrm{y}$ se incubó por 30 minutos, luego se corrió a $25 \mathrm{~V}$ y $300 \mathrm{~mA}$ por 30 minutos. Después de la electroforesis, las placas fueron lavadas con un buffer neutralizante por 5 , luego se tiñeron con $50 \mu \mathrm{lde}$ Bromuro de etidio $(0.02 \mathrm{mg} / \mathrm{mL})$. Las observaciones se realizaron en un microscopio de fluorescencia (Olimpus Cx41) equipado con filtro de $515-560 \mathrm{~nm}$ y un filtro de barrera de $590 \mathrm{~nm}$.

La ocurrencia de daño en el ADN se basó midiendo la longitud total del cometa haciendo uso del software (Tritek Comet ScoreTM freeware v1.5). La ocurrencia de daño en el DNA se basó en la longitud de la cola del cometa, inducida por la ruptura del ADN. Se consideró que la cola era producida por ruptura, si su longitud medía más de $41 \mu \mathrm{m}$ que es la longitud total producida por otros factores diferentes a ruptura. Se definió el rango para los tipos de daño de la siguiente manera: De 0 a $41 \mu \mathrm{m}$, tipo de daño $0=$ no daño; de 42 a $83 \mu \mathrm{m}$, tipo de daño $1=$ daño bajo; de 84 a $125 \mu \mathrm{m}$, tipo de daño 2 = daño medio y mayor a 126 $\mu \mathrm{m}$, tipo de daño 3 = daño alto. Como control positivo se utilizó el peróxido de hidrógeno $25 \mathrm{mM}\left(\mathrm{H}_{2} \mathrm{O}_{2}\right.$ $25 \mathrm{mM}$ ) y como control negativo se utilizó, el DMSO al 2\%, que fue el solvente de las muestras. Para medir la reproducibilidad de los resultados se hicieron tres experimentos por cada tratamiento y en cada uno se contaron 100 células. Para determinar la diferencia significativa entre el daño del control negativo y el de cada tratamiento se usa la prueba ANOVA a una vía.

\section{RESULTADOS Y DISCUSIÓN}

Como podemos observar en la tabla 1 , la viabilidad celular después del tratamiento se mantuvo por encima del $89 \%$, lo que nos indica que el daño en el ADN en las células se debe al tratamiento y no a otros 
factores que conducen a la muerte celular. Se establecieron categorías de daño para mostrar que este no se distribuye uniformemente en todas las células, lo cual puede ser una ventaja, debido a que la exposición no necesariamente afecta a todas las células, disminuyendo así el riesgo. Como, se puede observar en la tabla 1 , la longitud de la cola de las células tratadas con DMSO al $2 \%$ muestran un daño en promedio que no supera las $41 \mu$, en otras palabras, este valor representa el daño espontáneo. También podemos observar que la mayoría de las células $(92 \%)$ están en el rango de daño $0,(4,3 \%)$ en el rango $1 \mathrm{y}$ $(4,7)$ en el rango 2 , lo que muestra que únicamente un porcentaje muy bajo de células ( $8 \%)$, están dañadas. Los promedios de daño fueron incrementando significativamente comparado con el control a medida que se incrementó la dosis, con un valor $p<0.05$. De igual manera, con la dosis de $100 \mu \mathrm{g}$ se puede observar ya un incremento en el número de células dañadas ( $88 \%)$, siendo 1,2 y 3 los tipos los tipos de daño más frecuentes. Cabe resaltar que para esta dosis el tipo de daño más frecuente fue el 2 con un $45 \%$. También podemos observar en la tabla 1 que la dosis de $200 \mu \mathrm{g}$ induce con más frecuencia daños de tipo 2 y 3 , siendo el daño tipo 2 el más frecuente $(38 \%)$, encontrando ya un $93 \%$ de células dañadas. Se observa también en la tabla 1 que la dosis de $400 \mu \mathrm{g}$ induce daños de tipo 2 y 3 prioritariamente y que dicho daño ya se encuentra en el $68 \%$ de las células. De igual manera, podemos observar en la tabla 1 que las dosis que inducen mayor frecuencia de células con daño en el ADN también muestran mayor longitud de migración del
ADN (cola). Esto podría indicar que los genotóxicos que producen más daño en el ADN, también afectan a un mayor número de células. El daño encontrado en esta muestra de agua lo podemos atribuir a la presencia de residuos agroquímicos principalmente, pesticidas, dado que las fuentes que abastecen la planta de tratamiento, pasan por zonas agrícolas, dedicadas al cultivo de fresa y en las cuales se usan grandes cantidades de pesticidas. Según información suministrada por los agricultores de la zona los pesticidas más utilizados durante el periodo de cultivo de fresa en estudio son: clorpirifos, azoxystrobin, carbofuran, cipermetrina, pyraclostrobin, paraquat y glifosato; existe amplia evidencia que los asocia con la capacidad de generar daño a nivel del material genético; por ejemplo Rupturas en el ADN, aductos en el ADN, aberraciones cromosómicas e intercambio de cromátidas hermanas $28,29,30,31$. En estudios similares al nuestro, se ha reportado que la exposición a herbicidas e insecticidas, induce daño en el $A D N^{32}$; así mismo en un estudio realizado por $^{33}$ encontraron que trabajadores expuestos a mezclas de organofosforados, carbamatos y piretroides muestran daño en el ADN de linfocitos, muestran que pesticidas o mezclas de ellos causan daño oxidativo al $\mathrm{ADN}^{34}$ ya que se producen radicales que reaccionan con las membranas celulares e inician el proceso de peroxidación lipídica, la acumulación de estos radicales causa estrés oxidativo ${ }^{35}$. Iones metálicos presentes en algunos pesticidas interfieren con la reparación del ADN y producir especies reactivas de oxigeno (ROS), que conducen a daño oxidativo( ${ }^{(36)}$. 
Tabla 1. Resultados de la genotoxicidad inducida por agua antes de ingresar a la planta de tratamiento Empopamplona

\begin{tabular}{|c|c|c|c|c|c|c|c|}
\hline \multirow{2}{*}{$\begin{array}{c}\text { Tratam } \\
\text { iento }\end{array}$} & \multirow{2}{*}{$\begin{array}{c}\text { Prom } \\
\text { edio } \\
\pm \text { DS }\end{array}$} & \multicolumn{4}{|c|}{ Tipo de daño } & \multirow[b]{2}{*}{$\begin{array}{c}\% \text { de } \\
\text { célul } \\
\text { as } \\
\text { daña } \\
\text { das }\end{array}$} & \multirow{2}{*}{$\begin{array}{c}\% \text { de } \\
\text { Viab } \\
\text { ilida } \\
\text { d }\end{array}$} \\
\hline & & 0 & 1 & 2 & 3 & & \\
\hline $\begin{array}{l}\text { DMSO } \\
2 \%\end{array}$ & $\begin{array}{l}41 \pm \\
12\end{array}$ & $\begin{array}{c}27 \\
6\end{array}$ & $\begin{array}{l}1 \\
3\end{array}$ & $\begin{array}{l}1 \\
1\end{array}$ & 0 & 8 & 93 \\
\hline $\begin{array}{l}\mathrm{H}_{2} \mathrm{O}_{2} \\
25 \mathrm{mM}\end{array}$ & $\begin{array}{l}178 \\
\pm 18\end{array}$ & 35 & $\begin{array}{l}6 \\
4\end{array}$ & $\begin{array}{l}8 \\
1\end{array}$ & $\begin{array}{c}12 \\
0\end{array}$ & 89 & 90 \\
\hline $100 \mu \mathrm{g}$ & $\begin{array}{l}* 87 \\
\pm 10\end{array}$ & 37 & $\begin{array}{l}1 \\
0 \\
9 \\
\end{array}$ & $\begin{array}{l}1 \\
3 \\
5 \\
\end{array}$ & 29 & 88 & 89 \\
\hline $200 \mu \mathrm{g}$ & $\begin{array}{l}* 123 \\
\pm 13\end{array}$ & 17 & $\begin{array}{l}8 \\
0\end{array}$ & $\begin{array}{l}1 \\
1 \\
3\end{array}$ & 90 & 93 & 95 \\
\hline $400 \mu \mathrm{g}$ & $\begin{array}{l}* 185 \\
\pm 18\end{array}$ & 0 & $\begin{array}{l}1 \\
0\end{array}$ & $\begin{array}{l}8 \\
7\end{array}$ & $\begin{array}{c}20 \\
3\end{array}$ & 100 & 90 \\
\hline
\end{tabular}

Los resultados son expresados como la longitud de cola en $\mu \mathrm{m}$. Todos los valores provienen de 300 datos, obtenidos de tres experimentos independientes. Los rangos para los tipos de daño, se obtuvieron de la siguiente manera: De 0 a $41 \mu \mathrm{m}$, tipo de daño $0=$ no daño; de 42 a $83 \mu \mathrm{m}$, tipo de daño $1=$ daño bajo; de 84 a $125 \mu \mathrm{m}$, tipo de daño $2=$ daño medio y mayor a $126 \mu \mathrm{m}$, tipo de daño 3 = daño alto. Además se determinó el porcentaje de células dañadas y la viabilidad celular después de $1 \mathrm{~h}$ de tratamiento. Para determinar la diferencia significativa entre el daño del control negativo y el de cada tratamiento se usa la prueba ANOVA a una vía. *Diferencia significativa con $\mathrm{p}<0.05$

Tabla 2. Resultados de la genotoxicidad inducida por agua tratada con $\mathrm{Al}_{2}(\mathrm{SO} 4)_{3}$ en la planta de tratamiento Empopamplona.

\begin{tabular}{|c|c|c|c|c|c|c|c|}
\hline \multirow{2}{*}{$\begin{array}{c}\text { Tratam } \\
\text { iento }\end{array}$} & \multirow{2}{*}{$\begin{array}{c}\text { Prom } \\
\text { edio } \\
\pm \mathrm{DS}\end{array}$} & \multicolumn{4}{|c|}{ Tipo de daño } & \multirow{2}{*}{$\begin{array}{c}\% \\
\text { de } \\
\text { célul } \\
\text { as } \\
\text { daña } \\
\text { das }\end{array}$} & \multirow{2}{*}{$\begin{array}{c}\% \text { de } \\
\text { Viabil } \\
\text { idad }\end{array}$} \\
\hline & & 0 & 1 & 2 & 3 & & \\
\hline $\begin{array}{l}\text { DMSO } \\
1 \%\end{array}$ & $\begin{array}{l}41 \pm \\
12\end{array}$ & $\begin{array}{l}2 \\
6 \\
6\end{array}$ & $\begin{array}{l}1 \\
3\end{array}$ & $\begin{array}{l}1 \\
1\end{array}$ & 0 & 8 & 93 \\
\hline $\begin{array}{l}\mathrm{H}_{2} \mathrm{O}_{2} \\
25 \mathrm{mM}\end{array}$ & $\begin{array}{l}178 \pm \\
18\end{array}$ & $\begin{array}{l}3 \\
5\end{array}$ & $\begin{array}{l}6 \\
4\end{array}$ & $\begin{array}{l}8 \\
1\end{array}$ & $\begin{array}{l}1 \\
2 \\
0\end{array}$ & 89 & 90 \\
\hline $100 \mu \mathrm{g}$ & $\begin{array}{l}61 \pm \\
8\end{array}$ & $\begin{array}{l}8 \\
5\end{array}$ & $\begin{array}{l}1 \\
8 \\
0\end{array}$ & $\begin{array}{l}3 \\
0\end{array}$ & 5 & 72 & 91 \\
\hline $200 \mu \mathrm{g}$ & $\begin{array}{l}* 115 \\
\pm 9\end{array}$ & $\begin{array}{l}4 \\
0\end{array}$ & $\begin{array}{l}7 \\
5\end{array}$ & $\begin{array}{l}1 \\
6 \\
6\end{array}$ & $\begin{array}{l}1 \\
9\end{array}$ & 87 & 92 \\
\hline $400 \mu \mathrm{g}$ & $\begin{array}{l}* 192 \\
\pm 17\end{array}$ & 0 & $\begin{array}{l}3 \\
6\end{array}$ & $\begin{array}{l}6 \\
4\end{array}$ & $\begin{array}{l}2 \\
0 \\
0\end{array}$ & 100 & 94 \\
\hline
\end{tabular}

La tabla 2 nos muestra los resultados de la genotoxicidad inducida por agua tratada con $\mathrm{Al}_{2}(\mathrm{SO} 4)_{3}$ en la planta de tratamiento Empopamplona. Podemos darnos cuenta que la mayoría de los linfocitos presentan algún daño, así: la dosis de $100 \mu \mathrm{g}$ muestra un daño del $72 \%$, la dosis de $200 \mu \mathrm{g} 87 \%$ y la dosis de 400 $\mathrm{mg} 100 \%$; indicativo de que el agua tratada induce daño en el DNA de los linfocitos. Se observa cómo se incrementa el daño con respecto al control; nos damos cuenta que se aumenta en $1.5,2,8$ y 4,7 veces, según va incrementándose la dosis $y$ que estas diferencias son estadísticamente significativas con un $p<0,05$. Este daño observado posiblemente lo podemos atribuir a los procesos realizados en la planta de tratamiento, en donde se utiliza sulfato de aluminio como coagulante. En los lagos y lagunas, el $\mathrm{Al}_{2}(\mathrm{SO} 4)_{3}$ se usa con el fin de impedir el desarrollo de fitoplancton y así mejorar la transparencia del agua ${ }^{37}$, además, se utiliza para precipitar los sólidos en suspensión durante el tratamiento del agua, esta práctica induce en un incremento significativo en el metal; 
${ }^{38}$ encontraron que la adición de $\mathrm{Al}_{2}$ $\left(\mathrm{SO}_{4}\right)_{3}$ durante el tratamiento del agua para el consumo puede aumentar el nivel de 0,016 a 1,17 mg / L. Según estudios realizados se ha demostrado que es un metal tóxico cuya genotoxicidad se ha estudiado escasamente en las especies acuáticas y más en general en mamíferos. En un estudio realizado en el Lago Njivice, se demostró que el ensayo cometa alcalino tenía la sensibilidad adecuada para evaluar la niveles de daño en el ADN primordial en hemocitos de sanguijuela $H$. Verbana, se confirmó la toxicidad del medio acuático causada por contaminación antropogénica de aluminio $^{39}$; en las larvas del díptero Chironomus Riparius fueron demostradas diversas aberraciones cromosómicas ${ }^{40}$; así mismo, se han encontrado un aumento de daño en el ADN medido con el ensayo cometa en el pez Gambusia holbrooki $i^{41}$. Se ha demostrado que el aluminio induce aberraciones cromosómicas en células humanas 42,43. En linfocitos humanos cultivados 44 demostraron un aumento en la tasa de micronúcleos inducida por el metal, así como un aumento en el número de células apoptóticas. Otros autores también han evidenciado aberraciones cromosómicas, acumulación de células en la fase $\mathrm{S}$ e inhibición de la índice ${ }^{45,46}$.

Tabla 3. Resultados de la genotoxicidad inducida por agua tratada con cloro en la planta de tratamiento Empopamplona.

\begin{tabular}{|c|c|c|c|c|c|c|c|}
\hline \multirow{2}{*}{$\begin{array}{c}\text { Tratam } \\
\text { iento }\end{array}$} & \multirow{2}{*}{$\begin{array}{c}\text { Prom } \\
\text { edio } \\
\pm \mathrm{DS}\end{array}$} & \multicolumn{4}{|c|}{ Tipo de daño } & \multirow{2}{*}{$\begin{array}{c}\% \text { de } \\
\text { célul } \\
\text { as } \\
\text { daña } \\
\text { das }\end{array}$} & \multirow{2}{*}{$\begin{array}{c}\% \text { de } \\
\text { Viabil } \\
\text { idad }\end{array}$} \\
\hline & & 0 & 1 & 2 & 3 & & \\
\hline DMSO & $41 \pm$ & 2 & 1 & 1 & 0 & 8 & 93 \\
\hline $1 \%$ & 12 & $\begin{array}{l}6 \\
6\end{array}$ & 3 & 1 & & & \\
\hline
\end{tabular}

\begin{tabular}{|l|l|l|l|l|l|l|c|}
\hline $\mathrm{H}_{2} \mathrm{O}_{2}$ & $\begin{array}{l}178 \pm \\
25 \mathrm{mM}\end{array}$ & $\begin{array}{l}3 \\
18\end{array}$ & $\begin{array}{l}6 \\
4\end{array}$ & $\begin{array}{l}8 \\
1\end{array}$ & $\begin{array}{l}1 \\
2\end{array}$ & 89 & 90 \\
& & & & & 0 & & \\
\hline $100 \mu \mathrm{g}$ & $50 \pm$ & 1 & 8 & 2 & 6 & 38 & 91 \\
& 9 & 8 & 5 & 4 & & & \\
\hline $200 \mu \mathrm{g}$ & $* 92 \pm$ & 4 & 7 & 1 & 1 & 87 & 92 \\
& 7 & 0 & 5 & 6 & 9 & & \\
& & & & 6 & & & \\
\hline $400 \mu \mathrm{g}$ & $* 167$ & 0 & 3 & 6 & 2 & 100 & 94 \\
& \pm 15 & & 6 & 4 & 0 & & \\
\hline
\end{tabular}

En la tabla 3 podemos observar que la genotoxicidad también es dependiente de la dosis y que ese incremento es estadísticamente significativo con $p<0.05$. Si analizamos las dosis utilizadas, nos damos cuenta que indujeron daño, reflejado en el porcentaje de células dañadas, mostrando un $38 \%, 87 \%$ y $100 \%$ para las dosis de 100,200 y $400 \mu \mathrm{g}$ respectivamente. También nos podemos dar cuenta que el mayor tipo de daño que mostraron las células tratadas con $400 \mu \mathrm{g}$, fue el tipo de daño 3, que corresponde a daño alto, solamente un $21 \%$ de las células tratadas con esa dosis mostraron daño 2 , $12 \%$ daño 1 y ninguna de las células tratadas con esa dosis mostró daño 0 . Lo anterior nos indica que la exposición a dosis altas incrementa la probabilidad de inducir lesiones sobre el material genético. El efecto genotóxico inducido por esta muestra de agua lo podemos atribuir a los subproductos de la cloración principalmente, teniendo en cuenta que ya se conoce que cuando se utiliza cloro como desinfectante para el agua, este reacciona con material orgánico originando subproductos que puedan representar un riesgo genotóxico ${ }^{47}$. Se tiene evidencia que los subproductos de la cloración, especialmente el bromodiclorometano, clorodi brometano, bromoformo, ácido bromoacético, ácido cloroacético, ácido tricloro acético, 
20

bromato, cloronitrometano, bromonotrometano, dicloro nitrometano, dibromonitrometao, MX. EMX, N-nitrosopyrrolidine, formaldehyde, acetaldehyde, Chlorate, entre otros inducen genotoxicidad $^{23}$. Estudios previos han mostrado que los ácidos mono halo acéticos inducen ruptura de cadena en el ADN de células $\mathrm{CHO}$ y linfocitos humanos 48,49 y que el mecanismo de acción es a través de radicales de oxígeno ${ }^{50,51}$.

Teniendo en cuenta que el agua clorada surtida por la planta Empopamplona, atraviesa zonas agrícolas y caseríos, es muy probable que contenga residuos de contaminantes que no alcanzan a ser retenidos por el tratamiento (sedimentación, coagulación y filtración) y que serían los encargados de inducir el daño genotóxico en los linfocitos expuestos en nuestro estudio, además de lo ya mencionado, los procesos de coagulación y cloración por sí mismos, podrían estar aportando subproductos nuevos al agua de consumo, que también se encargarían de lesionar el material genético de las células utilizadas . Por esta razón y soportados en la evidencia que existe a nivel mundial, se puede concluir que el consumo de agua clorada puede ser uno de los factores de riesgo asociados al origen de enfermedades genéticas, especialmente el cáncer.

\section{BIBLIOGRAFIA}

1. Meléndez I, Zuleta M., marín i., Calle J., Salazar D. (2001). Efecto mutagénico de aguas de consumo Tratadas en la Planta Villa Hermosa.. Iatreia. , v.14, n.№ 3, p.167 - 175 .

2. Kummerer Klaus (2009). The presence of pharmaceuticals in the environmental due to human use-presentent knowledge and future challenges. Journal Environ Management. 1-13.
3. Collotta M, Bertazzi PA,Bollati V. (2013). Epigenetics and pesticides. Toxicology, pp 1-7.

4. Mostafalou S, Abdollahi M. (2013). Pesticides and human chronic diseases: Evidences, mechanisms, and perspectives. Toxicology and Applied Pharmacology, 268(2), pp 157-177.

5. United States Environmental Protection Agency (USEPA) (2004). Office of Pesticide Programs, H. E. D., Science Information Management Branch. Chemicals evaluated for carcinogenic potential.

6. IARC . International Agency for Research on Cancer (1991). Working Group. Occupational exposures in spraying and application of insecticides. IARC Monogr Eval Carcinog Risk Chem Hum , 53,pp 4592.

7. Morelli M. (2000). Industry viewpoint on thresholds genotoxic carcinogenic. Toxicol Pathol 28(3): 396-404.

8. Cabello G., Valenzuela M., Vilaxa A., Durán V., Rudolph I., Hrepic N., and Calaf C. (2001). A rat mammary tumor model induced by organophosphorous pesticides paration and malation, possibly through acetylcholineterase inhibition. Environ. Health Perspectives 109(5):471-479.

9. Recio-Vega $\mathrm{R}$, Velazco-Rodriguez $\mathrm{V}$, Ocampo-Gómez G, Hernandez-Gonzalez S, Ruiz-Flores P, Lopez-Marquez F. (2011). Serum levels of polychlorinated biphenyls in Mexican women and breast cancer risk. Journal of Applied Toxicology, 31(3) pp 270-278.

10. Schug TT, Janesick A, Blumberg B, Heindel JJ. (2011). Endocrine disrupting chemicals and disease susceptibility The Journal of Steroid Biochemistry and Molecular Biology, 127(3-5), ,pp 204215.

11. Kisby GE, Muniz JF, Scherer J, Lasarev MR, Koshy M, Kow YW, McCauley L. (2009). Oxidative Stress and DNA Damage in Agricultural Workers. Journal of Agromedicine, 14(2), pp 206-214.

12. McDonald, T.A., Komulainen, H., 2005. Carcinogenicity of the chlorination disinfection by-product MX. J. Environ. 
21

Sci. Health C Environ. Carcinog. Ecotoxicol. Rev. 23, 163-214.

13. IARC, International Agency for Research on Cancer, Monographs, Supplement (2012). Available from: 〈http://monographs.iarc.fr/ENG/Classif ication/index.php〉.

14. Díaz Moroles N. E., Alfaro Barbosa J. M., Garza Ulloa H. (2001). Método analítico para detectar hidrocarburos aromáticos policíclicos en agua potable. Ciencia UANL, Vol. IV, núm., 4, octubrediciembre, pp. 420-425. Monterrey, México.

15. Hrudey, S.E., Charrois, J.W.A. (2012). Disinfection By-products and Human Health. IWA Publishing, London.

16. Wei, J., Ye, B., Wang, W., Yang, L., Tao, J., Hang, Z. (2010). Spatial and temporal evaluations of disinfection by-products in drinking water distribution systems in Beijing, China. Sci. Total Environ. 408, 4600

17. Jurado, B., Ballesteros, E., Gallego, M. (2012). Occurrence of aromatic amines and N-nitrosamines in the different steps of a drinking water treatment plant. Water Res. 46, 4543-4555.

18. Papageorgiou, A., Voutsa, D., Papadakis, N. (2014). Occurrence and fate of ozonation by-products at a full-scale drinking water treatment plant. Sci. Total Environ. 481, 392-400.

19. Jurado, B., Ballesteros, E., Gallego, M., 2014. Occurrence of carboxylic acids in different steps of two drinking-water treatment plants using different disinfectants. Water Res. 51, 186-197.

20. Bove Jr., G.E., Rogerson, P.A., Vena, J.E (2007). Case-control study of the effects of trihalomethanes on urinary bladder cáncer risk. Archives of Environmental and Occupational Health 62 (1), 39e47.

21. Goebell, P.J., Villanueva, C.M., Rettenmeier, A.W., Rubben, H., Kogevinas, M. (2004). Environmental exposure, chlorinated drinking water, and bladder cancer. World Journal of Urology 21 (6), 424e432.

22. Villanueva, C.M., Cantor, K.P., Cordier, S., Jaakkola, J.J., King, W.D.,Lynch, C.F., Porru, S., Kogevinas, M. (2004). Disinfection byproducts and bladder cancer: a pooled analysis. Epidemiology 15 (3), 357e367.

23. Richardson SD, Plewa MJ., Wagner E.D., Schoeny R., DeMarini D.M. (2007). Occurrence, genotoxicity, and carcinogenicity of regulated and emerging disinfection by-products in drinking water: A review and roadmap for research,Mutat. Res. 636:178-242.

24. IARC, International Agency for Research on Cancer. (2004). Monographs on the Evaluation of Carcinogenic Risks to Humans Some Drinking-water Disinfectants and Contaminants, including Arsenic. Volume 84.

25. Xu.,Xu.,Zou Huixian and Zhang J. (1997). Formation of strong mutagen 3-cloro 4-(diclorometil) -5-hidroxí (5H) furanon (MX). By chlorination of fractions of lake water. Water Res. Vol.31 No 5:1021-1026.

26. Singh, NP, M McCoy, R Tice, and E Edward (1988). A simple technique for quantitation of low levels of DNA damage in individual cells, Exp. Cell Res.175: 184191.

27. Pandrangi R., Petras M., Ralph S., Vrzoc M. (1995). Alkaline single cell gel (commet) assay and genotoxicity monitoring using bullheads and carp. Environ Mol Mutagen. 26:345-356.

28. Lander BF, Knudsen LE, Gamborg MO, Jarventaus H, Norppa H. (2000). Chromosome aberrations in pesticideexposed greenhouse workers. [Comparative Study Research Support, Non-U S Gov't]. Scand J Work Environ Health, 26(5), pp 436-442.

29. Zeljezic D,Garaj-Vrhovac V. (2002). Sister chromatid exchange and proliferative rate index in the longitudinal risk assessment of occupational exposure to pesticides. Chemosphere, 46(2), pp 295303.

30. Grover P, Danadevi K, Mahboob M, Rozati R, Banu, BS, Rahman MF. (2003). Evaluation of genetic damage in workers employed in pesticide production utilizing the Comet assay. Mutagenesis, 18(2), pp 201-205.

31. Lee WJ, Blair A, Hoppin JA, Lubin JH, Rusiecki JA, Sandler DP, Alavanja MC. (2004). Cancer incidence among pesticide applicators exposed to 
chlorpyrifos in the Agricultural Health Study. J Natl Cancer Inst, 96(23), pp 17811789.

32. Giri S, Giri A, Sharma GD,Prasad SB. (2002). Mutagenic effects of carbosulfan, a carbamate pesticide. Mutation Research/Genetic Toxicology and Environmental Mutagenesis, 519(1-2), pp 75-82.

33. Bhalli JA, Khan QM, Nasim A. (2006). DNA damage in Pakistani pesticidemanufacturing workers assayed using the Comet assay. Environmental and Molecular Mutagenesis, 47(8), pp 587593.

34. Benedetti D, Nunes E, Sarmento M, Porto C, Santos CEI, Dias JF, da Silva J. (2013). Genetic damage in soybean workers exposed to pesticides: Evaluation with the comet and buccal micronucleus cytome assays. Mutation Research/Genetic Toxicology and Environmental Mutagenesis, 752(1-2), pp 28-33.

35. Collins AR, Oscoz AA, Brunborg G, Gaivão I, Giovannelli L, Kruszewski M, Štětina R. (2008). The comet assay: topical issues. Mutagenesis, 23(3), pp 143-151.

36. Bull S, Fletcher K, Boobis AR, Battershill JM. (2006). Evidence for genotoxicity of pesticides in pesticide applicators: a review. Mutagenesis, 21(2), pp 93-103.

37. Wauer, G., Heckemann, H., Koschel, R. (2004). Analysis of toxic aluminium species in natural waters. Microchim. Acta 146, 149-154.

38. DeVoto, E., Yokel, A.R. (1994). The biological speciation and toxicokinetics of Al. Environ. Health Perspect. 102, 940951.

39. Mihaljević, Z., Ternjej, I., Stankovic, I., Kerovec, M., Kopjar, N. (2009). Application of the comet assay and detection of DNA damage in haemocytes of medicinal leech affected by aluminium pollution: a case study. Environ. Poll. 157, 1565-1572.

40. Michailova, P., Ilkova, J., White, K.N. (2003). Functional and structural rearrangements of salivary gland polytene chromosomes of Chironomus riparius Mg. (Diptera, Chironomidae) in response to freshly neutralized
41. Ternjej, I., Mihaljević, Z., Stanković, I., Kerovec, M., Sipos, L., Zělježić, D., Kopjar, N. (2010). Estimation of DNA integrity in blood cells of eastern mosquitofish (Gambusia holbrooki) inhabiting an aluminium-polluted water environment: an alkaline comet assay study. Arch. Environ. Contam. Toxicol. doi:10.1007/s00244-010-9469-6.

42. Roy. A.K., Talukder. G., Sharma. A. (1990). Effects of aluminium sulphate on human leukocyte chromosomes in vitro, Mutat. Res. 244 (2) 179-183.

43. Kovačević, G., Gregorović, G., Kalafatić, M., Jaklinović, I. (2009). The effect of aluminium on the planarian Polycelis felina (daly). Water Air Soil Pollut. 196, 333-344.

44. Ternjej, I., Mihaljević, Z., Stanković, I., Kerovec, M., Sipos, L., Zělježić, D., Kopjar, N. (2010). Estimation of DNA integrity in blood cells of eastern mosquitofish (Gambusia holbrooki) inhabiting an aluminium-polluted water environment: an alkaline comet assay study. Arch. Environ. Contam. Toxicol. doi:10.1007/s00244-010-9469-6.

45. Roy. A.K., Talukder. G., Sharma. A. (1990). Effects of aluminium sulphate on human leukocyte chromosomes in vitro, Mutat. Res. 244 (2) 179-183.

46. Banasik.A., Lankoff .A., Piskulak. A., Adamowska. K., Lisowska. H., Wojcik. A. (2005). Aluminum-induced micronuclei and apoptosis in human peripheralblood lymphocytes treated during different phases of the cell cycle, Environ. Toxicol. 20 (4) 402-406.

47. Lima. P.D., Leite. D.S.,. Vasconcellos. M.C., Cavalcanti. B.C., Santos. R.A., Costa. L.V. Lotufo, C. Pessoa, M.O. Moraes, R.R. Burbano. (2007). Genotoxic effects of aluminum chloride in cultured human lymphocytes treated in different phases of cell cycle, Food Chem. Toxicol. 45 (7) 1154-1159.

48. Schiliro T., Pignata C., Rovere R., Fea E., Gill G. (2009). The endocrine disrupting activity of surface wáter and wastewaterntreatment plant, effluents in relation to chlorination. Chemosfere. 75:335-340. 
49. Komaki, Y., Pals, J., Wagner, E.D., Marinas, B.J., Plewa, M.J. (2009). Mammalian cell DNA damage and repair kinetics of monohaloacetic acid drinking water disinfection by-products. Environmental Science and Technology 43 (21), 8437e8442.

50. Escobar LF., Hoyos LE., Londoño E., Reyes I., Saavedra D., Carvajal S., Sánchez A., Wagner ED and Plewa M. (2013). Genotoxic and clastogenic effects of monohaloacetic acid drinking water disinfection by-products in primary human lymphocytes. water research 47 : 32 8-3290.

51. Ali A., Kurzawa-Zegota M., Najafzadeha M, Gopalana RC., Plewa MJ., Anderson D. (2014). Effect of drinking water disinfection by-products in human peripheralblood lymphocytes and sperm. Mutation Research 770: 136-143.

\section{Iván Meléndez Gélvez}

Ph.D. InvestigadorAsociado.

Universidad de Pamplona. Colombia, Facultad de Ciencias Básicas, Grupo de Investigación en Biología Molecular.

\section{Enrique Pardo Perez}

Ph.D.Profesor Asociado.Universidad de Córdoba, Montería, Córdoba, Colombia. Área de Genética, Departamento de Biología

\section{Alfonso Quijano Parra}

Ph.D.Investigador

Asociado.

Universidad de Pamplona, Colombia, Facultad de Ciencias Básicas, Departamento de Química. Grupo de Investigación en Química 